\title{
Students Development during Intensive Practical Work in Schools for the New "ACADEMIA-CLASS" Training Program
}

\author{
Smadar Galili \\ Elementary School, The David Yellin Academic College of Education, Jerusalem, Israel \\ *Corresponding author: smadarg@dyellin.ac.il
}

\begin{abstract}
The research's aim was to focus on 8 students teachers during the first year of implementation of the "Academia-Class" program, (attached to schools for three days per week instead of one day) and are full partners in the work of the classroom teachers. The research findings reveal satisfaction on the part of the schools and the students teachers with the inventiveness and variety displayed by the students teachers in the classes, their considerable acquaintance with various pupils and the progress achieved by the pupils. The collaboration created between the cooperating teachers and the students teachers are still superficial at this stage.
\end{abstract}

Keywords: students teachers, cooperating teachers, practice and theory, professional learning community, professional development school, partnership

Cite This Article: Smadar Galili, "Students Development during Intensive Practical Work in Schools for the New "ACADEMIA-CLASS" Training Program.” American Journal of Educational Research, vol. 5, no. 3 (2017): 296-302. doi: 10.12691/education-5-3-10.

\section{Introduction}

Following the academicization processes undergone by all the colleges of education in Israel, the hours of practical experience and didactics were considerably reduced and the theoretical studies were expanded. The emphasis on the theoretical learning is liable to lead to the avoidance of dealing with emotional and social aspects in the training processes, aspects which can have a major bearing on the future pedagogical conduct of the students in their functioning as teachers [3,27]. Together with this fact, research studies show that many teachers who leave the teaching profession during the first 5 years of their work took on themselves a heavy work load without seeking help [14]. This work load creates tension and burnout, which make it difficult for some of the new teachers, including those who were outstanding in the training processes [23], to develop their professional identity and to cope successfully with the challenges and difficulties which confront them. The difficulties and problems presented above require the teacher trainers to give additional thought on how to adapt the training processes to challenges facing new teachers in the educational field [3,33], thereby facilitating the passage from training to teaching and reducing the number of teachers leaving teaching during the first 5 years. The planning and construction of the "Academia-Class" program, which is the focus of this research study, represents an attempt by the Ministry of Education in Israel to deal with the abovementioned problems; in this program students teachers are integrated in schools in the course of their training as a significant part of the school teaching staff. The students, in their third year of training, spend three days per week in the schools (instead of one day), and are meant to become full partners in the work of the classroom teachers whilst still undergoing the training process. This research study focuses on 8 students teachers from the elementary school track who are participating for the first time in the Academia-Class program, and its aim is to examine what happens to them in the course of their year's training in the framework of the "Academia-Class" program?

\section{The Process of the Transition from Training to Teaching}

The encounter of the new teachers with the reality in the educational field is described in somber terms as a situation of survival of the "sink or swim" variety [35], which creates among a part of the new teachers feelings of helplessness, loneliness, strangeness and alienation [6], which lead to as many as 50 percent of them abandoning the profession in the first five years of their work [27]. These are significant years in the personal and professional lives of the new teachers, and the experiences which they go through have a critical impact on the development of their careers [24]. The professional identity of the teacher training graduates, which was developed in the course of their study years, and includes educational values, attitudes and norms, occasionally clashes with the demands and policy of the Ministry of Education which they come across in the initial stages of their work in the schools $[9,10,26,27,33]$ add that the professional development of students and teachers occurs 
more deeply and significantly in the course of the work in the educational field, and not during the academic studies. All that has been mentioned above reinforces the need for intensifying the links between the educational field and the academic training, with the aim of facilitating the absorption of new teachers in the schools, improving and strengthening their professional development and their ability to implement what they have learnt in the course of their training. In view of this, there was developed and implemented for this the first year (2015-2016) in Israel the "Academia-Class" program which we shall discuss in detail in the following section.

\section{The "Academia-Class" Training Program}

The "Academia-Class" training program, which is the focus of this research study, proposes a model of partnership between the educational field and academe. The aims of the program are to improve and promote the training processes of the students teachers and to facilitate their future entry and integration into the educational field, on the one hand, and to develop a professional learning community jointly for the schools and the academic teacher training colleges, on the other hand. In the partnership program between the teacher training college and schools one can discover a fruitful balance between all the partners - students, cooperating teachers and pedagogical advisors-, which enables them to be in a learning process and professional development $[12,29]$. Turning the school into a training base for the students teachers enables a fresh definition of its role, from acting purely as a field for the implementation of the practical experience only, into an equal partner in the practice of teaching [34]). Such a partnership is liable to advance the day-to-day educational practice of the cooperating teachers and the students, to build joint values, to develop a professional identity and to contribute to the organization as a whole [36]. [13], and [16] add that models of partnership between the educational field and academic teacher training colleges facilitate and promote the critical examination of the various educational processes and foster models of cooperation between the teachers and the students teachers. The cooperation includes mutual experience and reflective thinking that is likely to lead to real and meaningful changes in the schools and promote educational reforms such as the "Academia-Class" reform [37]. Furthermore, the cooperative learning enables participation in dialogue, enriches and improves the coping with varied problems, supports the absorption of new teachers and significantly reduces their anxieties $[2,8]$.

In the aforesaid "Academia-Class" partnership model, the students teacherstaught during their third year of training as a second teacher in a class 3 days per week, between 12-16 hours (instead of one day -6 hours), next to an experienced teacher (cooperating teacher), in a developing and controlled process. The practical experience of the students under real conditions, with intensity and continuity, enabling them to authentically experience events in the educational field, is likely to contribute to their more effective and easy future integration into the education system and to their perseverance in it $[18,19]$. Furthermore, it may be possible to empower the experienced teachers and their professional development through familiarization with the variety of educational insights, strategies and up-to-date teaching tools, which the students teachers bring with them from their college studies. Thus, it will be possible to promote a variety of significant and innovative teaching and learning procedures in the schools [38].

\section{Methodology and Methods}

\subsection{The Research Population}

Eight students teachers from the Elementary School Track, in their third year of training, volunteered to join the "Academia-Class" program in the course of their practical experience. This meant that they had to stay in the school for three days -12- 16 hours per week - instead of one day. The eight students teachers underwent their practical experience in the framework of the "AcademiaClass" program in two schools - "Nitzanim" and "Ofakim" - 4 students in each school.

\subsection{The Research Method}

In order to carry out this research study, the qualitative research approach was chosen, whereby it is possible to research a variety of different interpretations of the students teachers, the cooperating teachers, the pedagogical advisors and the school principals in the schools in which the program is being implemented [2,35]. As a researcher working on the basis of the interpretative paradigm, I chose the qualitative constructivist methodology, since my research focused on complex processes for the participants in it and does not seek unequivocal answers. By means of this methodology, I have attempted to arrive at an understanding of the reality being researched, based on interpretative contact with the partners in the research, eight students teachers from the elementary school track participating in the "Academia-Class" program, with their cooperating teachers, the school principals, and the pedagogical advisors.

\subsection{The Research Tools}

The data were collected from the start of the process of preparation for the implementation of the "Academia-Class" program during the months May-September 2015 and until the end of the school year, in the schools in which the program was implemented - June 2016. The data collection was carried out by means of semi-built-in interviews [1] with the students teachers, with the aim of learning how they experience their long stay in the schools in the course of the implementation of the program, and what problems they encounter, and what inner struggles do they have [5], and by means of feedback and reflections which the students teachers wrote during the school year $[17,30]$. In addition, throughout the year there were held semi-built-in in-depth interviews with the pedagogical advisors, the cooperating teachers and the school principals, with the goal of learning and understanding how they experienced the processes undergone by the students teachers. During 
the year the researcher held participatory observations in two meetings of the cooperating teachers in the framework of their professional development during the program. In these meetings intermediate assessments of the program were made in which the cooperating teachers had the opportunity to disclose the difficulties and strong points which they experience with the students teachers in the course of the implementation of the program. In addition, the researcher held external observations on all the students participating in the "Academia-Class" program during the lessons they taught in the classes, and in the feedbacks they received from the cooperating teachers and the pedagogical advisor after the lessons.

All participants volunteered to take part in the research study knowing that their names and any identifiable information would be removed from the data, they would be assigned pseudonyms, and they would be able to withdraw from the research at any time.

\subsection{Data Analysis}

The data collected in these in-depth interviews, the observations and the reflective journals, was transcribed and analyzed according to the principles of subject matter analysis which relates to the students teachers, the students' cooperating teachers, the pedagogical advisors and the school principals, of their thoughts, emotions and beliefs and the descriptions as a reflection $[1,31]$.

\subsection{Contribution of the Research}

It must be remembered that the research focused on eight students only, who were experiencing this first year of the "Academia-Class" program, and therefore it is important to avoid coming to far-reaching conclusions in the wake of its findings [28]. Nevertheless, it is possible that, from the analysis of the research findings, which present a complex and in-depth picture of the processes which these students underwent in the course of this year, the decision-makers in the Ministry of Education will be able to receive significant information and learn about the strong points of the program being implemented for the first year in Israel, and about aspects that will require improvement subsequently.

\section{Results and Discussion}

The results present a complex and many-faceted picture of the various processes, which the students teachers underwent in course of the school year from their personal viewpoint, from that of their cooperating teachers, the school principals and the faculty advisors.

\subsection{Comparison with Previous Practical Experience}

"I am no longer a shadow, an alien or a guest, I am a part of the class.."

All the students are happy with the choice they made to participate in the "Academia-Class" program, and feel sure that they are gaining much from it: "Rakefet: Once I was like a decoration in the classroom, and now I feel like a part of the system..." Maayan tells that the intensive start of the year in the classes made her feel excited and confident that she had chosen the right profession- the teaching profession: "I am learning like I have never learnt ever: how to begin the year and how to know the class, learn the needs of each pupil. We didn't have this in the previous experience... You want to be there till the very end.. I am enthusiastic because I feel that I have chosen the right thing and the right profession." It seems that these data corroborate the claim of $[15,23]$ that the more the student teacher feels confident in her ability to act as a good teacher, so she will feel more certain about her choice of the teaching profession. Tal maintains that she learnt in the first two months what she hadn't learnt in the course of two full years: "The most meaningful learning is through experience. This is the most meaningful year in my opinion... I am developing my educational persona and my educational credo." Galit presents the difficulty and burden together with feelings of pride and satisfaction: "There is no doubt that the fact that we are there three days per week is a huge difference. I feel that although it is tiring and demanding, but, in fact, that is what we have come for. I feel that it really does contribute, I really feel what it means to be a teacher"Maayan adds that she is coping well with the heavy workload demanded of her both in college and in the school.She finds great significance in her work, and the heavy workload no longer is a problem for her: "In the beginning I was very afraid, but now I feel a real need. I don't come because of the college and the demand but because I am committed to the children. When they talk to me, it warms my heart." A great deal of satisfaction can be noticed among the educational staff in the two schools - principals, pedagogical advisors and cooperating teachers - with the functioning of most of the students:: "One sees their development within the school, one sees a student and a teacher standing together in front of the class, one sees lessons which they conduct together. (Rivka, principal of the Ofakim School)" Tehila, the pedagogical advisor in the school, really discerns a significant difference between the students teachers participating in the Academia-Class program in her group and those who are not: "There is a significant difference between the students teachers taking part in the Academia-Class program and the rest. They are really like classroom teachers in their commitment to the class, they know the regulations and the children, manage to cope better with problems of discipline in the class, and the pupils take them more seriously. The other students are less familiar with the pupils, and take them less seriously." Geula, the cooperating teacher of Galit, adds." Galit is accepted as a teacher in every respect. If I look at the process since the beginning of the year, I have to say that I have found a real colleague, wanting to succeed and focused on the goal".

\subsection{The Partnership Contacts with the Cooperating Teacher}

The role of the cooperating teachers in the course of the practical experience is critical and significant [13]. Research studies prove that quality instruction, which 
includes giving constructive and supportive feedback, is the key to the success of novice teachers and to the marked reduction of their apprehensions [15,21,28].

\subsubsection{A Warm Welcome and Good Communication}

In the first months of their presence in the classes in the framework of the "Academia-Class" program, all the students testify to a very good rapport with the cooperating teachers. They testify to a warm and meaningful encouragement from the cooperating teachers at difficult moments, and participation in the warm welcome they received in both schools. "Maayan: The educational staff in the school received us with open arms... see in us teachers to all intents and purposes, and give advice and direction whenever needed." Ella tells that the encouragement of her cooperating teacher is very important to her whenever she experiences difficult moments: "The encouragement of Nurit, and the pat on the shoulder to indicate that I had helped her and that I had managed to read the situation and help her, contributed to helping to improve the mood and the motivation... Thursday was a very difficult day, and again the support and understanding of Nurit helped me to think optimistically and to remember the goal for which I had come to learn education, and which is to educate and shape the coming generation." Moreover, Rachel, who in the past had experienced differences of opinion and difficulties with training teachers, notes with satisfaction the positive connection she has had with Nava, the cooperating teacher, since the beginning of the process: "She received me with a warmth and cooperation which I didn't expect, and I was pleasantly surprised. We work together and she gives me the feeling that I can say whatever I think, and do in the class whatever I choose." Some of the students teachers tell that the cooperating teachers update them about what is happening in the class on the days when they are not there: " I am in contact with Orit, so that also on those days when I am not in the class I am updated, and in general, concerning every question, problem, advice, she gives me a sense of belonging and concern in that she always points out to the pupils that I am also part of the staff (Lea-student teacher)".

\subsubsection{The Nature of the Cooperative Relations: "We divided the work between us according to the year's schedule."}

In one school, "Ofakim", the partnership relations in most of the classes did not rise to a level of mutual cooperative learning (partnership) [11]. Partnership is meant to be the very heart of the educational organization, and its significance is the possibility of the team members to be both teachers and pupils at the same time, with each one contributing from his professional knowledge and experience [11,37]. These things find expression in innovative pedagogies, which the students bring with them from their college studies to the classrooms, and in processes of consultation in which the cooperating teachers see them as wise colleagues who assist them in making decisions. The nature of the partnership relations in this school, in three of the four classes, remained at the level of division of tasks between the cooperating teachers and the student teachers, without any instruction processes, consultation or cooperative teaching. Orit, the cooperating teacher, tells: "We divided the work between us according to the annual schedule... Each week there is at least one lesson whose contents she (the student) is responsible for and prepares by herself." The extent of cooperation is still very superficial: the student teacher "gives" a lesson and the cooperating teacher watches, the teacher teaches and the student teacher helps certain children or gives pupils support through individual work with them. [13,16], maintain, following a broad survey of the literature which they undertook on the contacts between cooperating teachers and students teachers, that cooperating teachers prefer to make do with support and giving compliments to the students teachers rather than in setting goals for further learning and professional development. The cooperative work between the teachers and the students teachers in the schools is not sufficient to be satisfied only with the consolidation process and the sense of togetherness, which give a feeling of confidence and contribute to a pleasant and easy atmosphere. It is important to also develop joint values, professional identity and common teaching goals [37], by means of which it will be possible to go deeper and learn how to improve the teaching methods and adapt them to the needs of the various pupils, and to focus on achieving these goals $[8,11]$. It will very likely also lead to changes in the teaching procedures of the cooperating teachers themselves, as well as in their beliefs and professional identity [13]. Instructing the students teachers represents for the cooperating teachers a unique opportunity for learning and professional development [28], but very often they do not receive suitable training for their important role [13]. Moreover, different models of partnership between teachers are likely to significantly advance educational reforms [37], like the "Academia-Class" reform, but, despite the ideal conditions for joint mutual learning, the cooperating teachers frequently tend to stick to their old outlooks and reject any possible new learning [20]. In "Ofakim" School, it was a lack of the joint instruction sessions, which were supposed to be held regularly in the school, whereas the cooperating teachers don't feel the lack of these meetings, and prefer instead to deal with urgent daily matters related to their commitment to the pupils in their class [13]. On the other hand, in the second school in which the program is being implemented, "Nitzanim", the cooperating teachers sit in instructional meetings with all the students teachers at a regular weekly meeting or in occasional meetings throughout the school year, and the school principal and the school coordinator ensure that they are held. It seems that in this school there are no differences between the cooperating teachers and the students teachers regarding the joint mutual learning experience: "We are very flexible on this issue, we meet one day for several hours, plan for the coming month, and then during the month every week or two we progress with the lesson we have planned or the teaching unit (Galit-student teacher)."Geula, the cooperating teacher of Galit, adds: "I am amazed and learn from the games which she brings from the college to the individual lesson for example. Frequently when I consult with her she is available at any moment and hour, and this greatly helps me. I value her opinion..." Nava, the cooperating teacher, describes the 
joint work with Rachel: "Rachel is a real teacher colleague. I feel that I am consulting with her about what we will do like a colleague, and involve her in all that is happening. She pays attention to the class, to things that I have not noticed."In addition, Rachel, for her part, says the following: "Nava enriches me ceaselessly with knowledge and "methods" for managing and coping with various situations in the class." All the students teachers in this school feel like full partners in the work of the cooperating teacher. "I think that I am an inseparable part of the class, really an additional classroom teacher of the pupils who is fully involved in the life of the class and in all that happens in it... that is my general feeling." It appears that the joint instructional sessions bear fruit, and in addition to the mutual learning and cooperation between the students and the cooperating teachers, the students feel involvement and partners to what is happening in their classes, and even take responsibility for various teaching processes and prepare in advance activities and lessons over and above the weekly lesson they have to teach. It seems that these data prove that allocating a set time $[8,21]$, for joint meetings of the cooperating teachers and the students teachers for support and meaningful guidance by experienced teachers, makes a big impact on the personal feeling of the students teachers, on the consolidation of their professional identity, and on the feeling of confidence which they acquired during this period [23]. All of these prove that close quality support and instruction contribute greatly to the development of the professional identity of the students teachers, to their feeling of having chosen the right profession, and they are anxious to continue and develop in it [15]. At the same time, the data gathered from the students teachers reinforce the findings of the research of [15] who maintain that most of the interactions between cooperating teachers and students teachers focus on the teaching contents, on strategies and imposing authority, but they are lacking in all the aspects relating to personal training which concentrate on developing and fostering the reflective, professional and emotional capacities of the students teachers.

\subsection{Up-to-date Pedagogy - Relating to Differences among Pupils and Teaching in a Heterogeneous Class}

After about five months of the implementation of the "Academia-Class" program in the two schools, observations were held in the classes in which the program was being implemented. I watched students teachers who were teaching like teachers in the classes to all intents and purposes, varying their teaching methods, and relating in a special way to the differences between the pupils in the heterogeneous class. This is knowledge, which the students teachers acquire during their college training, and in this way, it may be possible to promote a variety of meaningful and innovative teaching and learning procedures in the schools [38].

\subsubsection{Varying the Teaching Methods}

In all the classes in which I observed, the students teacherstaught with great confidence, and it was apparent that they were very well acquainted with the class and the pupils, and well-versed in the study material. These findings show that possibly the spending of much time by the students teachers in the classes achieves the goal of "adapting the training processes to field-focused teaching" ("Academia-Class," p.2), enables them to acquire experience and to deal correctly and in their own unique way with varied situations in the course of their teaching $[18,19]$, taught a crowded and heterogeneous Grade 1 class with calm confidence: "The children cooperate and answer her questions. Rachel is relaxed even though there is a bit of noise in the class. She asks questions, sticks to the rules, takes note of each reaction of a pupil, and relates to it seriously. She activates pupils who are not concentrating on the lesson. There is a serious discussion about the lesson which Rachel leads, and also her coping with the noise is impressive - she is not pressured and conducts the lesson in a relaxed manner. Her relaxed manner influences the pupils."

The data gathered in the course of the observations in the various classes testify, in addition to the professional and personal confidence acquired by the students teachers in this period, also to the combination of pedagogical updatedness and innovation, which they have brought with them from their studies in the college. It appears that we have here the achievement of one part of the additional goal set by the developers and initiators of the "AcademiaClass" program - "encouraging innovation in teaching and learning" [[38], p2]. All the students teachers who I observed had prepared an interesting lesson, special and challenging, in which they inserted a variety of teaching methods. "Galit had prepared a game to sum up a learning topic. The class is divided into two groups who compete with each other for mastery of the knowledge of the material they have learned." Rachel, who teaches in Grade 1, chose to teach the subject of masculine and feminine: "She began the lesson with a challenging question to the pupils based on the study of a picture, held a conversation on a high level with the pupils following questions which she put to them, and afterwards gave a concluding activity in three levels, requiring the pupils to read, sort, cut out and write." Also in the second school, "Ofakim", in the observations which I held, I could clearly see a variety in the methods of teaching: "There is here a challenging opening to the lesson by means of the flight tickets, and a meaningful discussion with the pupils [12], work with heterogeneous groups, a cooperative task for heterogeneous groups, and a conclusion in the form of a quiz for all the pupils." Nurit, the cooperating teacher, tells about the long process, which the class underwent until it was possible to teach such a varied lesson as today's: "It was an excellent lesson with both a game and also work in groups." Leah reports in a feedback following a lesson she taught: "In every subject I try to bring the innovation, and how I believe that one should teach." Also Hadass, the coordinator of the program, supports the findings of the observations: "My impression is that the students teachers are the ones who bring pedagogical innovation to the school. This is a reinforcing situation for them."

\subsubsection{The Attitude to Differences among the Pupils}

The central subjects, which the teachers have to deal with during the cooperative teaching are: improving teaching 
and learning methods, raising achievement standards, and improving motivation among the pupils [25]. Yet, many teachers in elementary education, who see in teaching adapted to the needs of the various pupils a significant and central goal of their teaching, find it hard to implement this goal in the teaching processes in their classes [4]. The findings gathered show that the students teachers participating in the "Academia-Class" program succeed in combining in their adaptive teaching strategies which they have learned in the college, and come to pupils who, as a rule, the classroom teacher has no time for, the population of pupils who 'fall between the stools'. They manage to form meaningful relations of trust with some of the pupils and achieve impressive results with them. Nava, the cooperating teacher tells: "Rachel pays attention to the children who, so far, I have not paid attention to, and her presence is very meaningful for them." Ora, the cooperating teacher in the Second Grade maintains that "There is a real progress of the pupils who I, as a rule, do not manage to get to. They receive personal response and assistance in the classroom." In all the observations that I carried out there is clear reference by the students teachers to the variance between the pupils in the class: "Rachel takes note of every reaction of a pupil and treats it seriously. She activates pupils who are not concentrating on the lesson... she moves around between the pupils and is attentive to their needs. She comforts a crying girl quietly and calmly, and hugs her." In addition, Rachel takes care to prepare tasks at three levels, which will suit the different levels of the pupils in First Grade: "The lesson is varied and adapted to different levels of pupils. Rachel has prepared tasks in three levels, and the strongest pupil begins with the second task." Geula, the cooperating teacher testifies that also in her class Galit makes a signal contribution to the pupils with difficulties: "Galit takes groups of children of foreign workers who, thanks to her, receive extra help." Also in the second school, "Ofakim", the personal contact which the students manage to create with the class pupils is strikingly evident. Ella, who found it very difficult to teach in the Fifth Grade, in which there were many behavioral problems in the course of the first two months, confides in a feedback following the lesson she has taught: "I am in a very safe place. I really enjoy coming here There were times when it was very hard for me to come because of all the problems (of the pupils), and now I come with motivation There were some successes on the way, and, in particular, personal conversations with the pupils as well as the individual work are what helped me the most to feel that the pupils are with me.. one of the most troublesome pupils from the behavior standpoint told me, "You won't leave me, you will be with us until the end of the year"... and a child who did not function at all, began today to take out an exercise book and write in this lesson."

\section{Conclusion}

\subsection{Development of Partnership Models}

Seeing that various models of partnership and cooperation are liable to help in significantly advancing educational reforms such as "Academia-Class" [28,37], we must help the faculty advisors to accompany and instruct the cooperating teachers in establishing and jointly building the models of partnership and mutual learning between them and the students teachers [8]. The partnership models must be developed significantly, and to turn them from mutual support into joint learning and professional cooperation. The cooperating teachers should be helped to set before the students teachers significant goals for achieving, and which will enable them to develop and progress professionally [13]. From various research studies we may learn that the majority of interactions between cooperating teachers and students teachers focus on teaching contents, on strategies and on imposing authority, but they are lacking in all the aspects relating to individual coaching and which concentrate on the fostering and developing of the reflective, professional and emotional capacities of the students teachers [17]. The developers of the "Academia-Class" program should think of ways how to develop and also include these aspects in the cooperative instruction and teaching processes between the cooperating teachers and the students teachers. Observations and joint discussion of case studies, analysis of the daily activity in classes, as well as observing other classes, are likely to significantly improve the teaching methods of the teachers and the mutual cooperative learning between them and the students teachers. All of these are likely to strengthen and tighten the connections between the experience, the theory and practice, and the "practical wisdom" [19]. Possibly, a part of the development programs for the professional staff built by the academic colleges in coordination with the schools and activated by them, have not yet achieved the level of development and reinforcement required for the cooperating teachers. Teacher training colleges have to take upon themselves the task of improving and deepening the training of the cooperating teachers in accordance with the principles and goals presented above, because there are within their walls the professional people with the knowledge and experience to carry out such training processes [13].

\subsection{Pedagogical Innovation}

Since the research findings show that the students teachers successfully integrated in their teaching pedagogical innovation which they implemented as a result of their studies in various courses in the college, we have to think how this innovation can be learnt and implemented also by the cooperating teachers, so that it will be possible to promote a variety of significant and innovative teaching and learning processes in the schools [[38], p. 15]. Particularly prominent among the pedagogical innovations is the personal and professional attention paid by the students teachers to pupils with special needs, and the implementation of adaptive teaching strategies within the heterogeneous classes. Despite the fact that veteran teachers, because of their great experience, cope more successfully with the differences between the pupils in the class [4], the young students teacherswho participated in this research study also proved successful in this area. It appears that the program enables and facilitates a significant and qualitative implementation of the process 
of integrating pupils with special needs in classes " as a result of the addition of new teaching strength which will enable them to receive a more varied and personal attention" [[38], p. 15]. It is to be hoped that the prolonged practical experience will still enable the students teachers to continue to vary their teaching methods and to deepen the connection between practice and theory, without undergoing a process of socialization, which might adversely affect their work and the pedagogical innovation, which they are currently implementing successfully.

\section{References}

[1] Ayalon, Y., Tsabar Ben Yehoshua, N. (2009). The content analysis process in accordance with grounded theory in the field. In L. Kesso \& M. Kromer-Nevo (Eds.), Data analysis in qualitative research (pp. 359-383). Beersheva: Ben Gurion University Press.

[2] Bolam, R., McMahon, A., Stoll, L., Thomas, S. \& Wallace, M. (2005). Creating and sustaining effective professional learning communities. Nottingham: DFES.

[3] Bourke, T. Ryan, M. \& Lloyd, M. (2016). The discursive positioning of graduating teachers in accreditation of teacher education programs. Teaching and Teacher Education, 53, 10-19.

[4] Bruggink. Goei, S.L \& Koot, H.M. (2016). Teachers' capacities to meet students' additional support needs in mainstream primary education. Teachers and Teaching: theory and practice. Volume 22, Issue 4.

[5] Cohen, L., Manion, L. \& Morrison, K. (2000). Research methods in education (5th ed.). London: Routledge.

[6] Dvir, N., \& Schatz-Oppenheimer, O. (2011). Looking in the mirror: Constructing novice teachers' professional identity as reflected in their narratives. In O. Schatz-Oppenheimer.

[7] Maskit, D.\& S. Silbersturm (Eds.), To be a teacher (pp. 91-115). Tel Aviv: Mofet.

[8] Day, C. (1999). Developing Teachers: The Challenge of Lifelong Learning. London: Falmer Press.

[9] Elliot, J. (1991). Action research for educational change. Philadelphia: Open University Press.

[10] Eraut, M. (2004). Informal learning in the workplace. Continuing Education, 26(2), 247-273.

[11] Fielding, M. (1999). Radical collegiality: Affirming teaching as an inclusive professional practice. Australian Educational Research, 26, 1-34.

[12] Grossman, P., Hammerness, K., \& McDonald, M. (2009). Redefining teaching, re-imagining teacher education. Teachers and Teaching, 15, (2), 273-289.

[13] Hoffman, V.J. Wetzel, M.M. Maloch, B. Greeter, E. Taylor, L. Dejulio, S. \& Vlach, K.S. (2015). What can we learn from studying the coaching interactions between cooperating teachers and preservice teachers? A literature review. Teaching and Teacher Education, 56, 99-112.

[14] Hong, J. (2012). Why do some beginning teachers leave the school, and others stay? Understanding teacher resilience through psychological lenses. Teaching and Teacher Education, 18, 417-440.

[15] Izadinia, M. (2015). A closer look at the role of mentor teachers in shaping preservice teachers' professional identity. Teaching and Teacher Education, 52, 1-10.

[16] Kuh, Lisa K. (2016). Teachers talking about teaching and school: collaboration and reflective practice via Critical Friends Groups. Teachers and Teaching: theory and practice, 22(3), 293-314.
[17] Körkkö, M. Outi Kyrö-, A. \& Tuija T. (2016). Professional development through reflection in teacher education. Teaching and Teacher Education, 55, 198-206.

[18] Lee, S \& Schallert, D. (2016). Becoming a teacher: Coordinating past, present, and future selves with perspectival understandings about teaching. Teaching and Teacher Education, 56, 72-83.

[19] Lunenberg, M., \& Korthagen' F. (2009). Experience, theory, and practical wisdom in teaching and teacher education. Teachers and Teaching: theory and practice, 15, (2), 225-240.

[20] Louie, N. (2016). Tensions in equity- and reform-oriented learning in teachers' collaborative conversations. Teaching and Teacher Education, 53, 1-9.

[21] Lyman, L., \& Foyle, H.C. (1993). Cooperative Grouping for Interactive Learning.

[22] Washington D.C.: NEA: National Education Association.

[23] Lindqvist, P., \& Nordänger,U.K.(2016). Already elsewhere - A study of (skilled) teachers' choice to leave teaching. Teaching and Teacher education, 54, 88-97.

[24] Maskit, D., \& Yaffe, E. (2011). Novices evaluate themselves -on a clear day you can see it all. In O. Schatz-Oppenheimer, D. Maskit \& S. Sibersturm (Eds.), To be a teacher (pp. 117-150). Tel Aviv: Mofet.

[25] Maeroff, G.I. (1993). Team building for school change teacher. New York: Teachers' College Press.

[26] Millett, S. (1997). The transition from a student teacher into a beginning teacher. (Unpublished doctoral thesis). Tel Aviv University, Israel.

[27] Peleg, R. (1997). First year in teaching: Schools and supervisors in the induction process for beginning teachers. (Unpublished doctoral thesis). The Hebrew University. Israel.

[28] Rui Yuan.E, (2016). The dark side of mentoring on pre-service language teachers' identity Formation. Teaching and teacher Education, 55, 188-197.

[29] Schach, A. (2005). The pedagogical guide's role regarding the connection between the college and the field. In Zimran, I.(Ed.), The Itay Zimran book, a collection of essays by teachers of The David Yellin Teacher's College (pp.28-35). Jerusalem: The David Yellin Academic College of Education.

[30] Schon, A.D. (1983). The reflective practitioner: How professionals think in action. London: Temple Smith.

[31] Shkedi, A. (2003). Words of meaning- qualitative research-theory and practice. Tel-Aviv: Ramot.

[32] Shlasky, S., \& Alpert, B. (2006). Ways of writing qualitative research-from deconstructing reality to its construction as a text. Tel Aviv: Mofet.

[33] Smith, L.A., Anderson, V., \& Blanch, K. (2016). Five beginning teachers' reflections on enacting New Zealand's national standards. Teaching and Teacher Education, 54, 107-116.

[34] Taylor, W. (1969). Society and the education of teachers. London: Faber and Faber.

[35] Tsabar Ben Yehoshua, N. (2001). Interpretive research: from paradise to reality via crisis- immigrants as new teachers. In $\mathrm{N}$. Tsabar Ben Yehoshua (Ed.), Genres and tradition in qualitative research (pp. 443-468). Tel Aviv: Dvir.

[36] Vrieling, E van den Beemt, A., \&M. de Laat. (2016). what's in a name: dimensions of social learning in teacher groups. Teachers and Teaching: theory and practice, 22, (3), 273-292.

[37] Wijnia, L. Kurst, E.M Woerkom, M., \& Poeli, R.F. (2016). Team learning and its association with the implementation of competence-based education. Teaching and Teacher Education, 56, 115-126.

[38] Ministry of Education. (2014). A proposal for operating the "Academia-Class" program, partnership for the enhancement of teaching, in the years 2015-2016. 